\title{
Symptoms of depression impact the course of lung function in adolescents and adults with cystic fibrosis
}

\author{
Astrid Fidika*, Marion Herle and Lutz Goldbeck
}

\begin{abstract}
Background: Epidemiological studies report high rates of depression among patients with cystic fibrosis (CF). Assuming a causal relationship between depression and the progression of CF, our hypothesis is that elevated symptoms of depression would be a predictor of worse lung function after two years.

Methods: In the context of the TIDES study, 473 German patients with CF (age 12-53 years, FEV ${ }_{1} \%$ predicted $M=66.2$, range 13-137) completed the Hospital Anxiety and Depression Scale (HADS). Lung function (FEV ${ }_{1} \%$ predicted) was assessed at baseline and followed up two years later. Repeated measures analysis was performed involving the level of $\mathrm{FEV}_{1} \%$ and the level of depressive symptoms at baseline as independent factors and $\mathrm{FEV}_{1} \%$ at the 2-year follow-up as the dependent variable.

Results: Interaction between lung function and depression at baseline significantly affected the change in lung function at the 2-years observation interval. The largest decline in $\mathrm{FEV}_{1} \%$ occurred in depressed patients with good lung function at baseline. In contrast, patients without any clinically relevant depressive symptoms and with poor lung function at baseline showed a slight increase two years later.
\end{abstract}

Conclusion: The findings emphasise the need to screen patients with CF for symptoms of depression and to treat co-morbid depression.

Keywords: Cystic fibrosis, Depression, Lung function

\section{Background}

Forced expiratory volume in one second $\left(\mathrm{FEV}_{1} \%\right)$ is the key outcome in cystic fibrosis (CF) for monitoring the course of the disease [1]. Average rates of annual decline in $\mathrm{FEV}_{1} \%$ are reported to be between one and three per cent $[2,3]$. A range of biological risk factors such as infection with Pseudomonas aeruginosa or pancreatic insufficiency promote this decline [3-6]. Moreover, associations between pathophysiological processes, such as inflammation, and increased symptoms of depression were identified in the context of other medical conditions [7-9]. In addition, psychological factors might explain additional variance in the course of the disease, given their association with adherence to treatment.

\footnotetext{
* Correspondence: astrid.fidika@uniklinik-ulm.de

Department of Child and Adolescent Psychiatry/ Psychotherapy, University Ulm Medical Centre, Steinhoevelstr. 1, 89075 Ulm, Germany
}

Prevalence rates for depression range between 6.9\% in Europe [10] and 8.6\% in the US [11]. They therefore, point to a major public health issue worldwide. Recently, a German study found that nine per cent of adolescent and adult patients with CF show clinically relevant symptoms of depression, similar to the prevalence in the general population [12]. According to the international TIDES study involving nine countries [13], 10\% of adolescents and 19\% of adults with CF reported elevated symptoms of depression. It is important to address depression in the context of medical treatment for two reasons. First, depression is a recognised major mental health problem and is associated with poor quality of life [14]. Evidence-based treatments for depression are available $[15,16]$ and patients with CF should be given an opportunity to access these treatments. Depression is a known risk factor for poor adherence to treatment more particularly in the case of 
patients with chronic conditions [17]. Chronically ill patients who screened positive for symptoms of depression have a three-fold higher risk of not adhering to some degree to their medical treatment [18]. Symptoms of depression such as low mood, lack of energy or hopelessness may impair the patient's willingness and ability to adhere to his medical treatment plan. Selfmonitoring of CF-symptoms may be limited owing to depression and patients may find it difficult to identify situations where medical assessment and intervention would be appropriate. Poor adherence to the medical regime limits treatment effectiveness, promotes disease progression and may, ultimately, reduce survival [19].

Accordingly, previous research showed that the mental health state of patients with chronic lung diseases does indeed impact relevant medical outcomes. Patients with asthma or chronic obstructive pulmonary disease have better disease outcomes in the absence of co-morbid anxious or depressive disorders [20-22]. Likewise in patients with CF symptoms of depression are inversely associated with lung function $[12,22]$. Hence, patients with severely impaired lung function reported the highest levels of symptoms of depression. In a recent study the decrease in lung function over a 12 year period was associated with a deterioration in health-related quality of life (HrQoL). This is known to be inversely correlated with depression [23]. Another study found that specific HRQoL domains, i.e. the pain domain in the SF-36 questionnaire and the physical functioning domain in the Cystic Fibrosis Quality of Life Questionnaire, contributed prospectively to the prediction of the survival of adults with CF [24].

Summarizing the evidence from epidemiological studies, it could be argued that progression of CF drives comorbid depression. However, the association between depression and the course of the CF may be reciprocal but so far there have been no longitudinal studies that disentangled this relationship in patients with CF. To further investigate the association between depression and lung function in patients with CF, we prospectively examined the hypothesis that symptoms of depression would be a predictor lung function in a two-year followup assessment when controlling for baseline disease severity of the CF-related lung disease.

\section{Methods}

\section{Participants and procedure}

Self-reported symptoms of depression were assessed in the German arm of the international epidemiological study on depression and anxiety in patients with CF (TIDES) [12]. These data were used as baseline measures for the current longitudinal study. Medical data at baseline and two years later were retrieved from the patients' medical charts as documented in the German CF registry.

All patients consented to participate in this TIDES study and to the use of their individual medical data from the German CF registry. The IRB at the University of Ulm approved the study.

612 of the 670 patients participating in the German arm of the TIDES study, were treated in German CF centres and their data were stored in the German registry. Complete baseline data, which included HADS depression score and lung function, were available for 575 of these patients. As follow-up data on lung function two years later were not available for all patients, the study sample for the current longitudinal analysis comprised 473 patients. No information was available about reasons for follow-up losses, such as death of a patient. No differences in $\mathrm{FEV}_{1} \%$ at baseline were observed between the patients with complete follow-up data and non-complete data $(t=-1.61 ; d f=573 ; p=.108)$ or for symptoms of depression $(t=-1.95 ; d f=573 ; p=.052)$.

\section{Measures}

\section{Demographic and $\mathrm{FEV}_{1} \%$ data}

Demographic information (age, gender, professional status, and living situation) and $\mathrm{FEV}_{1} \%$ were retrieved from the annual reports of the CF clinics to the German CF registry. The $\mathrm{FEV}_{1} \%$ value closest to the patient's birthday was used as the indicator of lung function.

\section{Symptoms of depression}

Symptoms of depression were measured using the depression subscale of the Hospital Anxiety and Depression Scale (HADS) [25], a brief and easy-to-administer screening tool for assessing symptoms of anxiety and depression in medical populations. Any physical symptoms of depression confounding with a chronic illness, such as fatigue or headaches, were excluded. For the prior seven-day period, patients rate the magnitude of each symptom of seven core symptoms of depression on a four-point scale ranging from 0 to 3 . Raw scores are added and established cut-off scores distinguish between normal ( $0-7$ points), borderline ( $8-10$ points), and clinical symptom levels ( $\geq 11$ points) [25,26]. Many studies that use the HADS confirmed that it is valid for both clinical and community settings. Good psychometric properties have been demonstrated [26,27] for the German version, too [28].

\section{Statistical analyses}

First, all data were analysed descriptively. Frequencies of cases with elevated symptoms of depression using the established cut-off score (8 or higher) [25,28] were computed. 
To examine differences in change in lung function according to the status of depression and disease severity at baseline, a $2 \times 2$ repeated measures ANOVA was conducted with lung function at baseline $\left(\mathrm{FEV}_{1} \% \leq 40 \%\right.$ vs. $\left.>40 \%\right)$ and depression at baseline (HADS depression 0 to 7 vs. 8 or higher) as independent variables, and lung function ( $\mathrm{FEV}_{1} \%$ predicted) at follow-up as a dependent variable. Cut-offs for classification of $\mathrm{FEV}_{1} \%$ as severely limited range from $30 \%$ to $50 \%$. We chose the cut-off of $\leq 40 \%$, because it indicates a significant airflow limitation and is commonly used in other studies. Effect sizes $\left(\eta^{2}\right)$ were computed $\left(\eta^{2}>0.01\right.$ indicating small, $\eta^{2}>0.10$ medium, and $\eta^{2}>0.25$ large effects) [29].

As regression to the mean (RTM) is a relevant cause of misinterpretation of results based on repeated measures, we investigated RTM quantification in accordance with Barnett et al. [30]. Because the group of patients with and the group without elevated symptoms of depression showed a significant difference in their mean $\mathrm{FEV}_{1} \%$ at baseline $(t=8.29 ; p<.001)$, we computed RTM effects separately for both groups and then checked these results against the means of the change scores (follow-up $\mathrm{FEV}_{1} \%$ baseline $\mathrm{FEV}_{1} \%$ ) of the four sub-groups.

All statistical analyses were performed with IBM Statistics SPSS 20.0 for Windows.

\section{Results}

\section{Characteristics of the study sample}

The age of the patients at baseline assessment ranged from 12 to 53 years $(M=23.2, S D=8.6) ; 55.4 \%$ were male. Most of the patients were living with their family or their partner $(79.3 \%)$ and were in education or employment (in school $27 \%$, in job training $35.5 \%$, employed $21.9 \%$, unemployed $5.1 \%$, retired $10.4 \%$ ).

The patients' lung function data at baseline are presented in Table 1. Altogether, 38 (8\%) patients reported elevated levels of depression, with $21(4.4 \%)$ of them in the borderline range at baseline. $89(18.8 \%)$ patients had a severe lung disease at baseline $\left(\mathrm{FEV}_{1} \% \leq 40\right)$. Patients with elevated symptoms of depression differed significantly in their $\mathrm{FEV}_{1} \%$ (depressed: $M=44.33, S D=16.01$

Table 1 Lung function ( $\mathrm{FEV}_{\mathbf{1}} \%$ ) at baseline among the study sample and subgroups

\begin{tabular}{|c|c|c|c|c|c|}
\hline & $\begin{array}{l}\text { Study } \\
\text { sample } \\
(n=473)\end{array}$ & $\begin{array}{l}\text { FEV }_{1} \% \leq \\
40 \% ; \\
\text { depressed } \\
(n=21)\end{array}$ & $\begin{array}{l}\text { FEV }_{1} \% \leq \\
40 \% ; \text { not } \\
\text { depressed } \\
(n=68)\end{array}$ & $\begin{array}{l}\text { FEV }_{1} \%> \\
40 \% ; \\
\text { depressed } \\
(n=17)\end{array}$ & $\begin{array}{l}\mathrm{FEV}_{1} \%> \\
40 \% ; \text { not } \\
\text { depressed } \\
(\mathrm{n}=367)\end{array}$ \\
\hline Range & $13.7-137.3$ & $23.1-39.0$ & $13.7-39.7$ & $40.4-76.5$ & $40.1-137.3$ \\
\hline M & 66.2 & 32.2 & 31.4 & 59.6 & 74.8 \\
\hline SD & 24.7 & 4.8 & 6.5 & 11.1 & 20.0 \\
\hline$\leq 40 \%$ & 89 (18.8\%) & & & & \\
\hline$>40 \%$ & 384 (81.2\%) & & & & \\
\hline
\end{tabular}

vs. not depressed: $M=68.06, \quad S D=24.39 ; \quad t=8.292$; $p<.001)$ from the patients with no elevated symptoms.

\section{Depression and course of $\mathrm{FEV}_{1} \%$}

As expected, a significant main effect of time $(F=5.96$; $\left.p=.015 ; \eta^{2}=0.013\right)$ indicated an average decrease of about $3 \%$ in the $\mathrm{FEV}_{1}$ predicted in our study sample during the two year observation period (Figure 1). A significant effect of group affiliation $\left(F=118.18 ; p<0.001 ; \eta^{2}=0.43\right)$ is incidental due to the fact that $\mathrm{FEV}_{1} \%$ predicted was one baseline criterion for classification.

A significant group $\mathrm{x}$ time interaction effect $(F=5.44$; $\left.p=.001 ; \eta^{2}=0.034\right)$ reveals that in the four groups lung function changed differently over time. The mean lung function decreased in three of the four groups. The largest group, i.e. patients with moderate to good lung function without symptoms of depression at baseline, declined from $74.9 \%(S D=20.0)$ to $70.9 \%(S D=22.1)$ during the two years under observation. Depressed patients with moderate or good lung function at baseline showed the greatest decline of all four groups from an average of $59.6 \%(S D=11.1 \%)$ at baseline to $52.0 \%(S D=20.7 \%)$ two years later. Patients with poor lung function and symptoms of depression at baseline decreased on average a further $3.5 \%$ from $32.2 \%(S D=4.8)$ to $28.7 \% \quad(S D=4.9)$. Contrary to the expectations, severely ill patients without depression at baseline increased slightly from $31.2 \%$ ( $S D=$ $6.5)$ to $34.3 \%$ of the $\mathrm{FEV}_{1}$ predicted $(S D=17.09)$.

The estimated RTM effect was $+/-1.06$ for the groups of patients with symptoms of depression within the normal range $(n=435)$. It was $+/-2.66$ for the group with elevated symptoms of depression $(n=38)$. The observed average changes within the groups were higher than this score for each of the four corresponding subgroups: $\mathrm{FEV}_{1} \% \leq 40$, depressed $(M=-3.41 ; S D=5.26), \mathrm{FEV}_{1} \% \leq 40$, normal $(M=$ 2.86; $S D=18.28), \mathrm{FEV}_{1} \%>40$, depressed $(M=-7.03 ; S D=$ 16.75), and $\mathrm{FEV}_{1} \%>40$, normal $(M=-3.87$; $S D=12.36)$.

\section{Discussion}

This is the first study to examine the impact of depression on change in lung function, especially $\mathrm{FEV}_{1} \%$ predicted, in adolescents and adults with CF. The results show that clinically relevant symptoms of depression may increase the loss of lung function and that severely ill patients without depression are able to improve their lung function against the progressive trend of CF. Therefore, in a bio-psycho-social model depression should be considered as an important risk factor for disease progression in patients with CF. This backs the position that mental health is a relevant factor as already mentioned in the literature in conjunction with other chronic conditions that impair the respiratory system [20-22]. Given our prospective study design, assumptions may be made about causality. Moreover, the phenomenon of RTM in 


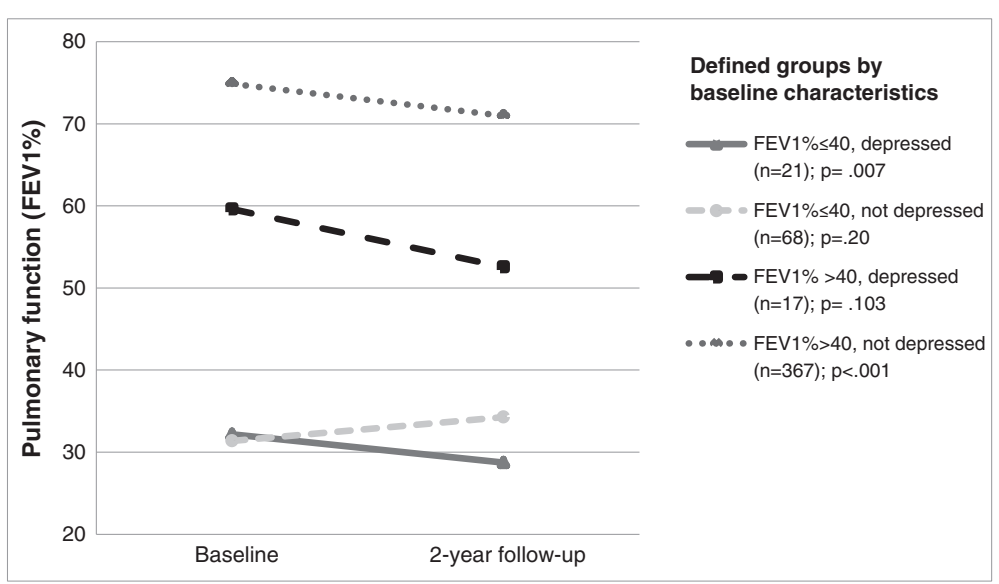

Figure 1 Change of $\mathrm{FEV}_{1} \%$ predicted over the period of two years, analyzed by level of lung function and state of depression at baseline $(n=473)$.

repeated measured data as a risk factor for misinterpreting results was taken into account. The estimated effects of RTM in the groups were lower than the observed changes in lung function. We can therefore, conclude that our findings are not solely based on RTM.

Our results are consistent with a theoretical model about the relationship between adherence, self-management behaviours and disease outcomes outlined by Modi et al. [31]. The interaction between depression and disease progression could be linked to the lack of hope, optimism and perceived self-efficacy in depressed patients, consequently inhibiting their fighting spirit against the disease and necessary adherence to treatment. Thus, depressed patients may fail to respond to standard medical treatment due to the nature of their mental health problems, and may experience a greater loss of lung function than necessary. This effect may then reinforce the negative thoughts related to their own prognosis, triggering a vicious psychosomatic cycle. In contrast, patients who are not depressed and already have severely restricted lung function might be more able to make use of resources for their daily treatment routines. This, in turn, might result in stable or even slightly improved outcomes.

Despite the strengths of this study, such as the relatively large sample size and the prospective design allowing for causal conclusions, some limitations may have biased our results. Due to study participants who were lost for follow-up for unknown reasons, a selection bias may have occurred in our results. However, our subgroup comparisons in what is still a relatively large sample for a rare condition like CF constitute a sound empirical basis for our results. The collection of data was based on registry data which may lead to limitations in interpretation [32]. More particularly, information about lung function ( $\mathrm{FEV}_{1} \%$ predicted) is not fully available over the two-year period in the registry because it is documented as a single-point measure in the observed year. This may cause higher individual variations than when using means or longitudinal data per year and does not allow for consideration of variability in patient lung function. Given the small number of patients in the groups, we were not able to control for confounders, such as CF-related diabetes or status of colonisation with germs. This, too, could perhaps had provided some substantial information to help explain the variance in the course of lung function within our sample. Due to the lack of feasibility in a routine clinical setting, symptoms of depression were assessed by self-reports only, and the persistence of these symptoms was not assessed. The use of HADS has been discussed controversially within the TIDES study [13]. The questionnaire was developed for use in medical settings and was deemed to be a valid and reliable screening measure when planning the TIDES study [26,27]. However, more recent studies report several shortcomings, such as underestimation of symptoms of depression [33,34]. Other valid and reliable screening questionnaires, such as PHQ-9 [33,35], might be a better choice for future studies and for use as a screening tool, as recently recommended by the International Guidelines Committee on Mental Health for Patients with CF and Their Caregivers [36]. Additionally, the generalisation of our results to patients in other countries warrants future investigation.

\section{Conclusions}

Our findings have several important clinical implications. Previous studies established that although there are substantial rates of co-morbid symptoms of depression in adolescent and adults with CF, not all patients receive treatment $[12,22]$. The current findings indicate that it is important to identify depressed patients and to offer them mental healthcare. Systematic screening 
procedures to identify patients needing treatment for their depression should become an essential component in the care of patients with $\mathrm{CF}$, as recently recommended by the International Guidelines Committee on Mental Healthcare for Patients with CF and Their Caregivers [36]. The Committee was sponsored by the European CF Society and the CF Foundation of the US and stressed the importance of targeting symptoms of depression and anxiety through appropriate intervention. Considering the importance of depression which is again emphasised by the results of the current study, treatment goals should include stabilisation of the patients' mood, behavioural activation, and the creation of a sense of self-efficacy.

Since no evidence-based interventions seeking to decrease the symptoms of depression specifically in patients with CF are available at the present time [22,37], those psychotherapeutic and psychopharmacological treatments known to be effective for patients with a primary diagnosis of depression should also be applied to patients with CF. However, in psychopharmacological treatment, possible reciprocal effects between CF medication and medication for depression have to be considered. Research efforts are needed to identify effective strategies for the delivery of treatments for depression in patients with $\mathrm{CF}$, and to evaluate their risks and benefits. Furthermore, strategies to help patients keep their lung function stable or even improve it might be an interesting topic for further studies in order to learn more about resources and successful coping strategies. Further research on the long-term effects of co-morbid depression and their impact on disease progression could be worth examining, for instance to establish whether they are of equal prognostic value for survival.

\section{Competing interests}

The authors declare that they have no competing interests ( $A F, M H, L G)$.

\author{
Authors' contributions \\ AF: contributed to the analysis of the follow-up data and drafting the \\ manuscript, interpreting the results, and approving the final version of the \\ manuscript. MH: contributed to interpreting the results, and approving the final \\ version of the manuscript. LG: contributed to designing the study, supervising \\ of the analyses, interpreting the results, and approving the final version of the \\ manuscript.
}

\footnotetext{
Acknowledgements

We thank Paul Wenzlaff at the Centre of Quality Assurance of the Medical Chamber of Lower Saxony for his support in accessing the medical follow-up data from the German CF registry. We also thank all the patients in the study, and the staff at the participating German CF centres for their help in collecting the data.

We thank the Research Arm of the German CF Association (Mukoviszidose Institut $\mathrm{GmbH}$ ) for funding the German part of the TIDES study.
}

Received: 12 August 2014 Accepted: 11 December 2014 Published: 16 December 2014

\section{References}

1. Davies JC, Alton EW: Monitoring respiratory disease severity in cystic fibrosis. Respir Care 2009, 54:606-617.

2. Liou TG, Elkin EP, Pasta DJ, Jacobs JR, Konstan MW, Morgan WJ, Wagener JS: Year-to-year changes in lung function in individuals with cystic fibrosis. J Cyst Fibros 2010, 9:250-256.

3. Taylor-Robinson D, Whitehead M, Diderichsen F, Olesen HV, Pressler T, Smyth RL, Diggle P: Understanding the natural progression in \%FEV1 decline in patients with cystic fibrosis: a longitudinal study. Thorax 2012 67:860-866

4. Konstan MW, Morgan WJ, Butler SM, Pasta DJ, Craib ML, Silva SJ, Stokes DC, Wohl MEB, Wagener JS, Regelmann WE, Johnson CA, Scientific Advisory Group and the Investigators and Coordinators of the Epidemiologic Study of Cystic Fibrosis: Risk factors for rate of decline in forced expiratory volume in one second in children and adolescents with cystic fibrosis. J Pediatr 2007, 151:134-139.

5. Kerem E, Viviani L, Zolin A, MacNeill S, Hatziagorou E, Ellemunter $H$, Drevinek P, Gulmans $V$, Krivec $U$, Olesen $H$, on behalf of the ECFS Patient Registry Steering Group: Factors associated with FEV1 decline in cystic fibrosis: analysis of the ECFS Patient Registry. EurRespir J 2014, 43:125-133.

6. VandenBranden SL, McMullen A, Schechter MS, Pasta DJ, Michaelis RL, Konstan MW, Wagener JS, Morgan WJ, McColley SA, Investigators and Coordinators of the Epidemiologic Study of Cystic Fibrosis: Lung function decline from adolescence to young adulthood in cystic fibrosis. Pediatr Pulmonol 2012, 47:135-143.

7. Numakawa T, Richards M, Nakajima S, Adachi N, Furuta M, Odaka H, Kunugi $\mathrm{H}$ : The role of brain-derived neurotrophic factor (BDNF) in comorbid depression: possible linkage with steroid hormones, cytokines, and nutrition. Front Psychiatry 2014, 5:136.

8. Lopresti AL, Drummond PD: Obesity and psychiatric disorders: commonalities in dysregulated biological pathways and their implications for treatment. Prog Neuropsychopharmacol Biol Psychiatry 2013, 45:92-99.

9. Dantzer R, O'Connor JC, Freund GG, Johnson RW, Kelley KW: From inflammation to sickness and depression: when the immune system subjugates the brain. Nat Rev Neurosci 2008, 9:46-56.

10. Wittchen HU, Jacobi F, Rehm J, Gustavsson A, Svensson M, Jönsson B, Olesen J, Allgulander C, Alonso J, Faravelli C, Fratiglioni L, Jennum P, Lieb R, Maercker A, van Os J, Preisig M, Salvador-Carulla L, Simon R, Steinhausen $\mathrm{HC}$ : The size and burden of mental disorders and other disorders of the brain in Europe 2010. Eur Neuropsychopharmacol 2011, 21:655-679.

11. Kessler RC, Petukhova M, Sampson NA, Zaslavsky AM, Wittchen HU: Twelvemonth and lifetime prevalence and lifetime morbid risk of anxiety and mood disorders in the United States. Int J Methods Psychiatr Res 2012, 21:169-184.

12. Goldbeck L, Besier T, Hinz A, Singer S, Quittner AL: Prevalence of symptoms of anxiety and depression in German patients with cystic fibrosis. Chest 2010, 138:929-936.

13. Quittner AL, Goldbeck L, Abbott J, Duff A, Lambrecht P, Solé A, Tibosch MM, Bergsten Brucefors A, Yüksel H, Catastini P, Blackwell L, Barker D: Prevalence of depression and anxiety in patients with cystic fibrosis and parent caregivers: results of The International Depression Epidemiological Study across nine countries. Thorax 2014, 69(12):1090-7.

14. World Federation for Mental Health: Depression: A Global Crisis. 2012 Available at: http://www.who.int/mental_health/management/depression/ wfmh_paper_depression_wmhd_2012.pdf. Accessed October 7, 2013.

15. von Wolff A, Holzel L, Westphal A, Harter M, Kriston L: Combination of pharmacotherapy and psychotherapy in the treatment of chronic depression: A systematic review and meta-analysis. BMC Psychiatry 2012, 12:61.

16. Cuijpers P, van Straten A, Schuurmans J, van Oppen P, Hollon SD, Andersson G: Psychotherapy for chronic major depression and dysthymia: a meta-analysis. Clin Psychol Rev 2010, 30:51-62.

17. Smith A, Krishnan J, Bilderback A, Riekert K, Rand C, Bartlett SJ: Depressive symptoms and adherence to asthma therapy after hospital discharge. Chest 2006, 130:1034-1038.

18. DiMatteo M, Giordani P, Lepper H, Croghan TW: Patient adherence and medical treatment outcomes: a meta-analysis. Med Care 2002, 40:794-811.

19. Felker B, Katon W, Hedrick SC, Rasmussen J, McKnight K, McDonnell MB, Finn SD: The association between depressive symptoms and health 
status in patients with chronic pulmonary disease. Gen Hosp Psychiatry 2001, 23:56-61.

20. Lavoie KL, Bacon SL, Barone S, Cartier A, Ditto B, Labrecque M: What is worse for asthma control and quality of life: depressive disorders, anxiety disorders, or both? Chest 2006, 130:1039-1047.

21. von Leupholt A, Taube K, Lehmann K, Fritzsche A, Magnussen H: The impact of anxiety and depression on outcomes of pulmonary rehabilitation in patients with COPD. Chest 2011, 140:730-736

22. Riekert K, Bartlett SJ, Boyle M, Krishnan J, Rand C: The association between depression, lung function, and health-related quality of life among adults with cystic fibrosis. Chest 2007, 132:231-237.

23. Abbott J, Hurley MA, Morton AM, Conway SP: Longitudinal association between lung function and health-related quality of life in cystic fibrosis. Thorax 2013, 68:149-154.

24. Abbott J, Hart A, Morton AM, Dey P, Conway SP, Webb AK: Can healthrelated quality of life predict survival in adults with cystic fibrosis? Am J Respir Crit Care Med 2009, 179:54-58.

25. Zigmond A, Snaith RP: The hospital anxiety and depression scale. Acta Psychiatr Scand 1983, 67:361-370.

26. Bjelland I, Dahl A, Haug T, Neckelmann D: The validity of the hospital anxiety and depression scale. An updated literature review. J PsychosomRes 2002 52:69-77.

27. Hermann C: International experiences with the hospital anxiety and depression scale - a review of validation data and clinical results. J Psychosom Res 1997, 42:17-41.

28. Hermann-Lingen C, Buss U, Snaith RP: HADS-D Hospital Anxiety and Depression Scale - German Version, 3rd Edition edn. Bern: Huber; 2011.

29. Bortz J, Doering N: Forschungsmethoden und Evaluation für Human-und Sozialwissenschaftler, 4th ed. edn. Heidelberg, Germany: Springer-Verlag; 2006.

30. Barnett AG, van der Pols JC, Dobson AJ: Regression to the mean: what it is and how to deal with it. Int J Epidemiol 2005, 34:215-220.

31. Modi AC, Pai AL, Hommel KA, Hood KK, Cortina S, Hilliard ME, Guilfoyle SM, Gray WN, Drotar D: Pediatric self-management: a framework for research, practice, and policy. Pediatrics 2012, 129:e473-e485.

32. Schechter MS: Benchmarking to improve the quality of cystic fibrosis care. Curr Opin Pulm Med 2012, 18(6):596-601.

33. Cameron IM, Crawford JR, Lawton K, Reid IC: Psychometric comparison of PHQ-9 and HADS for measuring depression severity in primary care. $\mathrm{Br} J$ Gen Pract 2008, 58:32-36.

34. Martin CR: What does the Hospital Anxiety and Depression Scale (HADS) really measure in liaison psychiatry settings? Curr Psychiatry Rev 2005, 1:69-73.

35. Cameron IM, Cardy A, Crawford JR, du Toit SW, Hay S, Lawton K, Mitchell K, Sharma S, Shivaprasad S, Winning S, Reid IC: Measuring depression severity in general practice: discriminatory performance of the PHQ-9, HADS-D, and BDI-II. Br J Gen Pract 2011, 61:e419-e426.

36. Smith BA, Goldbeck L, Georgiopoulos AM: Screening and assessment; psychological interventions; pharmacological interventions. Pediatr Pulmonol 2014, 49(S38):S171-S172.

37. Goldbeck L, Fidika A, Herle M, Quittner AL: Psychological interventions for individuals with cystic fibrosis and their families. Cochrane Database Syst Rev 2014, 6:CD003148.

doi:10.1186/1471-2466-14-205

Cite this article as: Fidika et al: Symptoms of depression impact the course of lung function in adolescents and adults with cystic fibrosis. BMC Pulmonary Medicine 2014 14:205.

\section{Submit your next manuscript to BioMed Central and take full advantage of:}

- Convenient online submission

- Thorough peer review

- No space constraints or color figure charges

- Immediate publication on acceptance

- Inclusion in PubMed, CAS, Scopus and Google Scholar

- Research which is freely available for redistribution 